\title{
A Complete Medical Education Includes the Arts and Humanities
}

\section{Citation}

Jones, D.S. "A Complete Medical Education Includes the Arts and Humanities." Virtual Mentor 16 (8): 636-641. DOI: 10.1001/virtualmentor.2014.16.08.msoc1-1408

\section{Published Version}

10.1001/virtualmentor.2014.16.08.msoc1-1408

\section{Permanent link}

http://nrs.harvard.edu/urn-3:HUL.InstRepos:23947104

\section{Terms of Use}

This article was downloaded from Harvard University's DASH repository, and is made available under the terms and conditions applicable to Open Access Policy Articles, as set forth at http:// nrs.harvard.edu/urn-3:HUL.InstRepos:dash.current.terms-of-use\#OAP

\section{Share Your Story}

The Harvard community has made this article openly available.

Please share how this access benefits you. Submit a story.

Accessibility 
What Can the Arts and Humanities Offer Medicine?

David S. Jones, M.D., Ph.D.

Of the many crises faced in health care today, one of the most troubling is the perceived loss of empathy among medical students and residents. Medicine, at

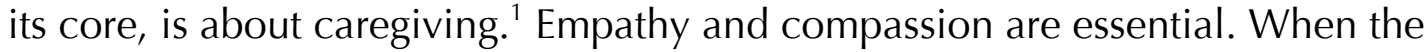
empathic connections between patients and doctors are broken, both patients and doctors suffer: patients receive worse care and physicians burn out. The causes of the problem have been described well. Students learn medicine within a health care system that does not prioritize caregiving. Instead, they admit patients, order and interpret tests, formulate treatment plans, and discharge those patients -sometimes within the same shift. Time pressures and a hidden curriculum value efficiency, not compassion.

Solutions to the problem are less clear. Educators have long worked to figure out the best ways to teach medical knowledge and skills (if the perpetual efforts to reform curricula are any indication, this remains a work in progress). What is at issue here, however, is a question of character. Empathy, along with compassion, sincerity, dedication, professionalism (whatever that means), and even just being a good listener, are all traits anyone would want in their doctor. These traits are likely as important as a physician's technical expertise. How can character be taught? Medical students are often taught how to act empathically, with a toolkit of gestures and utterances designed to convey concern. But everyone knows that there is a gulf between demonstrating empathy and being empathic.

Advocates for the arts and humanities in medicine have offered their disciplines as a partial solution to the challenge of character education. They argue that the arts and humanities can be used to teach empathy, professionalism, and other character competencies. While these approaches have value, they may actually undersell the contributions that the arts and humanities offer medicine.

Many authors have described how training in the arts and humanities can foster professionalism, listening skills, cultural sensitivity, ethics, empathy, or a commitment to humanism. ${ }^{2}$ Literature, for instance, challenges readers to see the world from the perspective of another person and develop empathy for the characters. This can help medical students and physicians in many ways. Practice at imagining oneself in another's shoes, for instance, can help a frustrated doctor sympathize with a non-compliant patient. Music, meanwhile, focuses attention on active listening. Some physician-musicians arrange performances for patients and find that this different way of being with patients transforms their interactions with them. ${ }^{3}$ Art can be adapted for many different purposes. By asking clinical teams to spend time with works of art and to work together as a team of non-experts to interpret a painting's mysteries, art educators can break down communication barriers within clinical teams and foster team work. The curiosity and questioning that follow when clinicians are presented with an artwork can model the curiosity and questioning required when clinicians encounter patients. ${ }^{4}$ Anthropology and 
history can teach students about the diversity of human experience across space and time. They force students to think seriously about their own values and perspectives, things they might otherwise take for granted.

The efforts to make the case for arts and humanities in medical education have had to grapple with the recent turn towards competencies and empirical assessments of educational outcomes. The Association of American Medical Schools recently sifted through 153 different lists of competencies from different institutions and distilled what it hopes will be a more coherent system of eight domains and fifty-eight competencies. ${ }^{5}$ Advocates for the arts and humanities often latch on Domain 5, Professionalism: "Demonstrate a commitment to carrying out professional responsibilities and an adherence to ethical principles." According to the leaders of one recent effort, the Project to Rebalance and Integrate Medical Education, "The major goal of medical education in ethics and humanities is to promote humanistic skill and professional conduct in physicians. Patient-centered skills enable learners to become medical professionals, whereas critical thinking skills assist learners to critically appraise the concept and implementation of medical professionalism.." ${ }^{\prime 6}$ The challenge there, as the authors admit, is how to show that professionalism has actually been taught.

Many groups have taken up the empirical challenge. One study, done as a collaboration between the Museum of Fine Arts in Boston and the Brigham and Women's Hospital, used an art education intervention to demonstrate that it was possible to train medical students to be more astute observers of radiological images. ${ }^{7}$ A recent analysis by the Narrative Medicine group at the College of Physicians and Surgeons at Columbia University used focus groups to characterize the ways in which training in narrative medicine can "support complex interior, interpersonal, perceptual, and expressive capacities." These skills "can bring patients and clinicians into authentic contact as a prelude to action. ${ }^{\prime 8}$

It is easy to understand why advocates of the arts and humanities have felt compelled to document the instrumental benefits of their disciplines. Competencies and empirical assessments have become the currency of the realm in the world of medical pedagogy. These efforts, however, raise many concerns.

Are the benefits conferred by training in the arts and humanities really things that can be measured? Psychologists and education researchers have developed validated scales of empathy, cultural sensitivity, professionalism, visual literacy, and much more. It is possible to use pre- and post-intervention surveys to demonstrate positive changes in these scales. But is that really what matters? Modern pedagogic gold standards often feel like a bureaucratized, reductionist, dystopia. Is medical education nothing more than a series of competencies, attainment of which can be documented by an improved score on a competency scale? And why is it that the arts and humanities have felt the need to engage in this game to create space for themselves in medical schools, while similar demands are not made on the traditional components of medical education? Most medical school courses have not been subjected to pre-post test evaluation. While final exams show that courses in anatomy and molecular biology teach medical students 
anatomy and molecular biology, no one has shown that this makes them better doctors. No one asks for evidence that surgery rotations improve measurable endpoints in the majority of students who do not become surgeons. Exposure to surgery, anatomy, and molecular biology are simply assumed (with good reason) to be an essential part of a complete medical education.

Would it be possible to assume that the arts and humanities are also an essential part of a complete medical education? Societies have valued the arts and humanities for as long as we have records of societies -- for millennia. These pursuits must provide some enduring value. In its 2013 report about the crisis facing the humanities and social sciences, the American Academy of Arts and Sciences made a powerful case that these disciplines are essential to civic life. ${ }^{9}$ They are "a source of national memory and civic vigor, cultural understanding and communication, individual fulfillment and the ideals we hold in common." The humanities "remind us where we have been and help us envision where we are going." They "foster creativity, appreciation of our commonalities and our differences, and knowledge of all kinds." The social sciences "reveal patterns in our lives, over time and in the present moment." They "they help us understand what it means to be human and connect us with our global community." Together the humanities and social sciences "go beyond the immediate and instrumental to help us understand the past and the future." If these things are valuable for civic society writ large, then they are valuable for medicine. Medicine, after all, is at the heart of the caregiving on which so much of society relies.

Much of the value that the arts and humanities offer to medicine cannot be reduced to simple measures. Literature, for instance, provides a mode of practice for difficult aspects of medical care. Medical students and physicians inevitably face difficult moral choices and other dilemmas in patient-doctor relationships. Would you, as a clinician, ever withhold a diagnosis from a patient if a family asked? Would you be willing to implement an advanced directive and withdraw life support from a dying patient? Bioethicists can teach arguments, rules, and expectations, but literature can often be more valuable. Students can encounter these dilemmas, in advance, through reading, whether fiction (e.g., Alberto Tyszka, The Sickness) or memoir (e.g., Philip Roth, Patrimony). When encountered through reading, students have the chance for sustained, thoughtful reflection, as well as the chance to appreciate and reconcile multiple perspectives. They will then be better prepared to respond well when they encounter these dilemmas on the wards..$^{10}$ I doubt that the value of this kind of reading, or the similar value of sustained engagement with poetry, art, or music, can be quantified in pre-post assessments.

There is another way in which the focus on character training and professionalism undersells the contribution of the arts and humanities. I can make the case best for the field I know best -- history. History of medicine need not be an exercise of documenting the triumphant march of medical progress, or of highlighting the lives of past clinicians as paragons of clinical value -- though this too can be useful. ${ }^{11}$ Instead, history of medicine can make fundamental contributions to medical knowledge. Medical students need to understand disease, 
but they are only taught aspects of its complexity (e.g., common manifestations, pathophysiology, underlying molecular biology, etc.). Others aspects of disease demand an understanding of social science. Why did tuberculosis decline in western Europe and the United States by $90 \%$ before the advent of antibiotics? Why have obesity rates in the United States doubled over the past generation? Answers to these questions cannot be found in a molecular biology class. Instead, the answers lies in the shifting social, economic, and political worlds that patients inhabit. ${ }^{12}$ Anyone who would claim to understand disease -- as doctors should -must understand the social determinants of disease. History, by asking students to consider carefully the mechanisms of disease change over time, can open their minds to the complex interactions between individual and society.

Doctors need similar perspective about therapeutic efficacy. ${ }^{13}$ What does it mean to say that a treatment worked? Doctors might be reassured by a favorable change in some biomarker, or confidence that the prescribed drug targets a relevant molecular pathway. Patients often have different assessments, whether an improvement in symptoms or relief simply from knowing that they are fighting the disease. When patients and doctors value different outcomes, they can end up with different assessments of efficacy, something that drives a wedge between them. The history of therapeutics demonstrates the complexity of efficacy. Pushing students to think seriously about why bloodletting remained popular for thousands of years, or why lobotomy rose and fell over twenty years, can help them to recognize the many factors that influence how doctors, patients, families, and societies judge the value of medical care.

The richer understanding of disease and therapeutics provided by history should be an essential part of medical education. ${ }^{14}$ I suspect that scholars and practitioners of the other arts and humanities can produce strong arguments for their own domains. These disciplines need not simply be instruments used to teach non-specific characters traits, such as empathy, teamwork, and professionalism. While they can do that, they can do much more.

\footnotetext{
${ }^{1}$ Arthur Kleinman, "Caregiving as Moral Experience," Lancet 380 (2012): 1550-1.

${ }^{2}$ Andrew W. Schwartz, Jeremy S. Abramson, Israel Wojnowich, Robert Accordino, Edward J. Ronan, and Mary R. Rifkin, "Evaluating the Impact of the Humanities in Medical Education," Mount Sinai Journal of Medicine 76 (2009): 372-380.

${ }^{3}$ Lisa M. Wong, From Scales to Scalpels: Doctors Who Practice the Healing Arts of Music and Medicine (New York: Pegasus Books, 2012).

${ }^{4}$ Alexa Miller, Michelle Grohe, Shahram Khoshbin, and Joel T. Katz, "From the Galleries to the Clinic: Applying Art Museum Lessons to Patient Care," Journal of Medical Humanities 34 (2013): 433-438.

${ }^{5}$ Robert Englander, Terri Cameron, Adrian J. Ballard, Jessica Dodge, Janet Bull, Carol Aschenbrener, "Toward a Common Taxonomy of Competency
} 
Domains for the Health Professions and Competencies for Physicians," Academic Medicine 88 (2013): 1088-1094.

${ }^{6}$ David J. Doukas, Laurence B. McCullough, and Stephen Wear, "Medical Education in Medical Ethics and Humanities as the Foundation for Developing Medical Professionalism," Academic Medicine 87 (2012): 334-341.

${ }^{7}$ Sheila Naghshineh, Janet P. Hafler, Alexa R. Miller, Maria A. Blanco, Stuart R. Lipsitz, Rachel P. Dubroff, Shahram Khoshbin, and Joel T Katz, "Formal Art Observation Training Improves Medical Students" Visual Diagnostic Skills," Journal of General Internal Medicine 23 (2008): 991-997.

${ }^{8}$ Eliza Miller, Dorene Balmer, Nellie Hermann, Gillian Graham, and Rita Charon, "Sounding Narrative Medicine: Studying Students' Professional Identity Development at Columbia University College of Physicians and Surgeons," Academic Medicine 89 (2014): 335-342.

${ }^{9}$ American Academy of Arts \& Sciences, The Heart of the Matter: The Humanities and Social Sciences for a Vibrant, Competitive, and Secure Nation (Cambridge: American Academy of Arts \& Sciences, 2013), available at http://www.amacad.org.

${ }^{10}$ Samyukta Mullangi, "The Synergy of Medicine and Art in the Curriculum," Academic Medicine 88 (2013): 921-923.

${ }^{11}$ Charles S. Bryan and Lawrence D. Longo, "Teaching and Mentoring the History of Medicine: An Oslerian Perspective," Academic Medicine 88 (2013): 97101.

${ }^{12}$ David S. Jones, Scott H. Podolsky, and Jeremy A. Greene, "The Burden of Disease and the Changing Task of Medicine," New England Journal of Medicine 366 (2012): 2333-2338.

${ }^{13}$ Jeremy A. Greene, David S. Jones, and Scott H. Podolsky, "Therapeutic Evolution and the Challenge of Rational Medicine," New England Journal of Medicine 367 (2012): 1077-1082.

${ }^{14}$ David S. Jones and Jeremy A. Greene, "Making the Case for History at Medical Schools," submitted to Journal of the History of Medicine and Allied Sciences, May 2014. 